\title{
Plantar pressure distribution of ostrich during locomotion on loose sand and solid ground
}

\author{
Rui Zhang Corresp., ${ }^{1}$, Dianlei Han ${ }^{1}$, Songsong Ma ${ }^{1}$, Gang Luo ${ }^{1}$, Qiaoli Ji ${ }^{1}$, Shuliang Xue ${ }^{1}$, Mingming Yang ${ }^{1}$, \\ Jianqiao Li ${ }^{1}$ \\ ${ }^{1}$ Key Laboratory of Bionic Engineering, Ministry of Education, Jilin University, Changchun, the People's Republic of China \\ Corresponding Author: Rui Zhang \\ Email address: zhangrui@jlu.edu.cn
}

Background. Ostrich is a cursorial bird with extraordinary speed and endurance, especially in the desert, and thus is an ideal large-scale animal model for mechanic study of locomotion on granular substrate.

Methods. The plantar pressure distributions of ostriches walking / running on loose sand / solid ground were recorded using a dynamic pressure plate.

Results. The center of pressure (COP) on loose sand mostly originated from the middle of the 3rd toe, which differed from the J-shaped COP trajectory on solid ground. At mid-stance, a high-pressure region was observed in the middle of the 3 rd toe on loose sand, but three high-pressure regions were found on solid ground. The gait mode significantly affected the peak pressures of the 3rd and 4th toes $(p=$ $1.5 \times 10^{-6}$ and $2.39 \times 10^{-8}$, respectively), but not that of the claw $(p=0.041)$. The effects of substrate were similar to those of the gait mode.

Discussion. Ground reaction force trials of each functional part showed the 3rd toe bore more body loads and the 4th toe undertook less loads. The pressure distributions suggest balance maintenance on loose sand was provided by the 3rd and 4th toes and the angle between their length axes. On loose sand, the middle of the 3rd toe was the first to touch the sand with a smaller attack angle to maximize the ground reaction force, but on solid ground, the lateral part was the first to touch the ground to minimize the transient loading. At push-off, the ostrich used solidification properties of granular sand under the compression of the 3rd toe to generate sufficient traction. 


\title{
$1 \quad$ Plantar pressure distribution of ostrich during locomotion on loose sand and solid ground
}

3 Rui Zhang*, Dianlei Han, Songsong Ma, Gang Luo, Qiaoli Ji, Shuliang Xue, Mingming Yang, Jianqiao $4 \quad \mathrm{Li}$

5

8 Corresponding Author:

9 Rui Zhang

Email: zhangrui@jlu.edu.cn

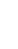

No. 5988 Renmin Street Nanguan District, Changchun, 130022, P.R. China

Key Laboratory of Bionic Engineering, Ministry of Education, Jilin University, Changchun, P.R. China

No. 598 Renmin Street Nanguan District, Changchun, 130022, P.R. China

\begin{abstract}
Background. Ostrich is a cursorial bird with extraordinary speed and endurance, especially in the desert, and thus is an ideal large-scale animal model for mechanic study of locomotion on granular substrate.
\end{abstract}

Methods. The plantar pressure distributions of ostriches walking / running on loose sand / solid ground were recorded using a dynamic pressure plate.

Results. The center of pressure (COP) on loose sand mostly originated from the middle of the 3rd toe, which differed from the J-shaped COP trajectory on solid ground. At mid-stance, a highpressure region was observed in the middle of the 3rd toe on loose sand, but three high-pressure regions were found on solid ground. The gait mode significantly affected the peak pressures of the $3 \mathrm{rd}$ and 4 th toes $\left(\mathrm{p}=1.5 \times 10^{-6}\right.$ and $2.39 \times 10^{-8}$, respectively), but not that of the claw $(\mathrm{p}=$ 
26 0.041). The effects of substrate were similar to those of the gait mode.

27 Discussion. Ground reaction force trials of each functional part showed the 3rd toe bore more 28 body loads and the 4th toe undertook less loads. The pressure distributions suggest balance 29 maintenance on loose sand was provided by the 3rd and 4th toes and the angle between their 30 length axes. On loose sand, the middle of the 3rd toe was the first to touch the sand with a 31 smaller attack angle to maximize the ground reaction force, but on solid ground, the lateral part 32 was the first to touch the ground to minimize the transient loading. At push-off, the ostrich used 33 solidification properties of granular sand under the compression of the 3rd toe to generate 34 sufficient traction. 
The effective locomotion of terrestrial animals depends on the interaction between the functional body parts and the substrate [1]. Evolution has pushed their environmental adaptation, so the limbs of animals living in different environments show various functional morphology and kinematics. Even the same animal may adopt substrate-specific locomotion strategies. For example, when running on solid surface, the desert-dwelling zebra-tailed lizard (Callisaurus draconoides) uses a digitigrade foot posture to recover about $40 \%$ of the whole mechanical work [2], but when running on granular surface, the lizard employs a plantigrade foot posture to paddle through granular substrate and generate enough force for acceleration $[2,3]$.

Despite the complicated interaction between limbs and the ground, recent studies demonstrate both walking and running gaits emerge from a spring-loaded inverted pendulum model, and the gait dynamics vary largely along with different combinations of kinetic energy, leg compliance and leg contact conditions, resulting in different oscillation modes [1, 41, 42]. As for walking, it involves an inverted-pendulum model that accounts for the efficient exchange between potential energy and kinetic energy within each step [4, 5]. Benefiting from this model, humans can not only save $70 \%$ of total mechanical work to move body mass at the optimal speed, but also carry up to $20 \%$ of body weight on the head without additional energy $[4,6]$. Moreover, as for rapid locomotion such as running, hopping and galloping, the center of mass (COM) is inverse to the walking gait, as it minimizes at the mid-stance and maximizes at the touchdown and take-off. Therefore, these bouncing gaits are described as a spring-mass model that accounts for the exchange of mechanical energy. In the spring-mass model, mechanical energy is stored as elastic strain in spring-like tissues (e.g. tendons) at the first half of the stance phase, and then returned by elastic recoil at the second half $[4,5,7]$. Moreover, the spring-mass model could approximate the gait stability of a mammal or bird running on diverse terrains $[8,9]$. Although the inverted-pendulum model and the spring-mass model both represent rather simple mechanical systems, these fundamental mechanisms have been observed in humans, birds, cockroaches and lizards, and are utilized to carry out the projects of various bionic robots [9-13].

These models all simplify the substrate as a rigid, flat and perfectly elastic ground, but in reality, natural substrates such as sand, soil and snow display both solid-like and fluid-like features [3]. During movement on natural substrates, solid-fluid transition happens beyond the yield stress and then results in increasing the energy cost and instability of gait [14]. Furthermore, comprehensive models are less well-developed to predict the reaction and leg kinematics on granular substrates than solid substrates. As we all know, soft substrates significantly affect the 
results.

In order to study locomotion on flowing substrates, researchers proved granular dry sand was an ideal substrate, because it displayed both solid-like and fluid-like behaviors and was simpler than other flowing substrates such as snow and soil $[15,16]$. Many small and light desert animals, such as lizards, were utilized to study the locomotion mechanics on granular sand because of their high locomotion performance on a wide range of desert terrains [17-19]. It was found natural variation in substrate mechanics did not greatly affect the sprinting performance of either C. draconoides or Uma scorparia.

Moreover, recent studies on the interaction between small legged robots and granular materials (e.g. sand) reveal the effective locomotion on granular materials depends on the solidification properties of the granular substrate $[20,21]$. This dependence is partially attributed to the fact that below the yield stress, the forced granular substrate remains solid, but beyond the yield stress, it flows like a fluid. Based on the solidification mechanism, we can explain and predict the rapid legged locomotion on sand by using empirical models [3]. For example, sea turtles, only by using solidification properties of sand under the flippers, can crawl on loose sand at a speed three times the body length per second without any slip [22, 23].

Falkingham reconstructed the 3D foot movements of guineafowl traversing a granular substrate from biplanar X-rays, and then incorporated the kinematics into a discrete element simulation [44]. As the soil thickness increased, footprints gradually became shallower and the force acting on sand also decreased. However, these changes can only be qualitatively described.

Relevant literatures are focused on small animals, which are convenient for trials. However, plantar pressures in large animals have not been reported. African ostrich (Struthio camelus) is an ideal model for locomotion research of large and heavy animals on natural surfaces, as this highly-specialized cursorial bird has extraordinary speed and endurance [24, 25]. This large terrestrial bird moves faster than other ratites and has been filmed running at the speed of 60 $\mathrm{km} \cdot \mathrm{h}^{-1}$ for 30 minutes, with a peak of $80 \mathrm{~km} \cdot \mathrm{h}^{-1}[24,25]$. Ostriches live in deserts, especially semiarid deserts with short grasses, and inhabit about $25 \mathrm{~km}^{2}$ territories [26]. In order to survive in deserts, ostriches locomote efficiently on diverse substrates (e.g. sand, rocks and grass) to find enough food and water. Compared with bipedal humans, ostriches run at two times speeds with about $50 \%$ lower of metabolic cost, although both species have similar weight and height [27, $28]$.

This efficient locomotion of ostriches is mechanically supported by the extended jointed 
102

103

104

105

106

107

chain system of their hindlimbs with the center of mass close to the hip, which maximizes the gravitational and elastic potential energy [25]. Long and slender tendons, coupled with the flexion and extension of joints, store and return a large proportion of mechanical energy, which would otherwise be compensated by muscle power [24, 28, 29]. The permanently elevated metatarsophalangeal joint (MTP) (Fig. 1) is a highly-specialized structure for transforming kinetic energy and gravitational potential energy into elastic strain energy of muscle-tendon units, which accounts for the majority of elastic energy stored in this joint [24, 28]. Furthermore, the longest hindlimb among ratites, in combination with proximally- concentrated muscles, endows ostriches with high stride frequency and large step lengths [29, 30].

(1)

2

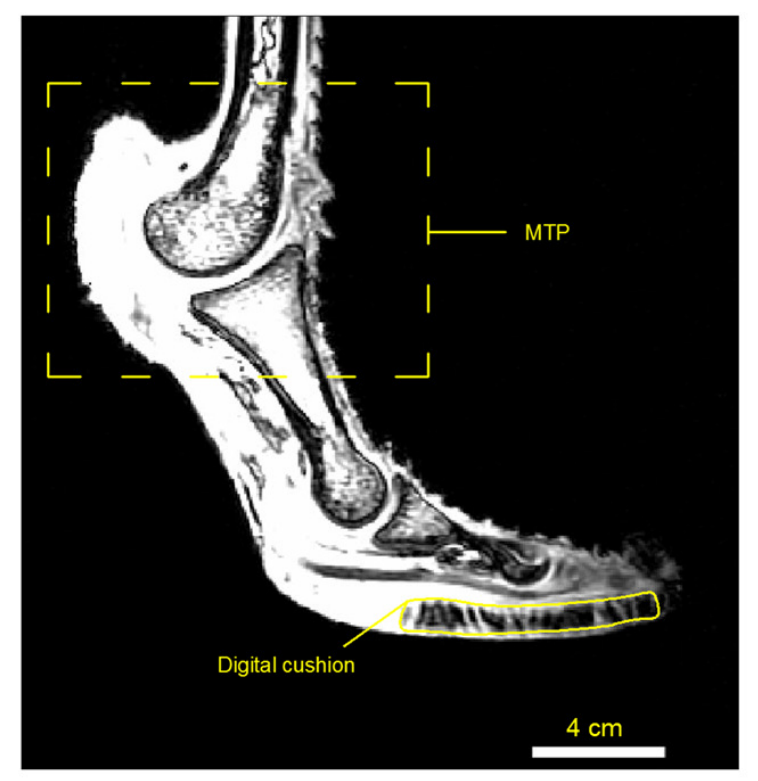

Fig. 1. MRI image of the ostrich foot with the MTP and digit cushion.

(1)

The adaptation of rapid locomotion can also be observed in ostrich foot toes. Each ostrich foot has only two digits (the 3rd and 4th toes) covered with closely adherent vertical cornified papillae, whereas other ratites have three digits with simple callous plantar pads [30]. The 3rd toe has two approximately parallel digit cushions (Fig. 1) that are fixed by fibrous connective tissues and extend from the 1 st to the 4th phalanxes, while the 4th toe has only one cushion under the phalanxes [31]. A recent study on dynamic pressure distribution of ostrich locomotion on solid ground reveals the 3 rd toe bears the most loads of the body mass, the 4th toe is responsible for 
122 stabilization and the claw functions as a position anchor [32]. Despite many suggestions about 123 ostrich running rapidly on various terrains, no study has examined the mechanism how the two 124 toes interact with granular materials.

125 In this study, we explored the plantar pressure distributions of ostrich toes, and assessed the 126 functions of toes when ostriches ran / walked on two typical and well-defined substrates (loose 127 sand and solid ground) that were similar to the habitat environment of ostriches.

\section{Materials and Methods}

\section{Animals}

Ten healthy juvenile ostriches with healthy feet were selected from a local breeder. Ethical approval was given by the Animal Experimental Ethical Inspection, Jilin University (reference No. 3130089). These ostriches were kept outdoor. Each ostrich was trained to walk and run on a fenced-in corridor for at least 30 minutes each time, twice per day, and over a month before data collection. After comprehensive comparison of representation and amenability, we selected two tractable female adult ostriches to finish all tests. Other female ostrich feet were brought from a slaughter house and then scanned by magnetic resonance imaging (MRI). The three-dimensional reconstruction and MRI images of the feet are shown in Figs. 1 and 2, respectively. 


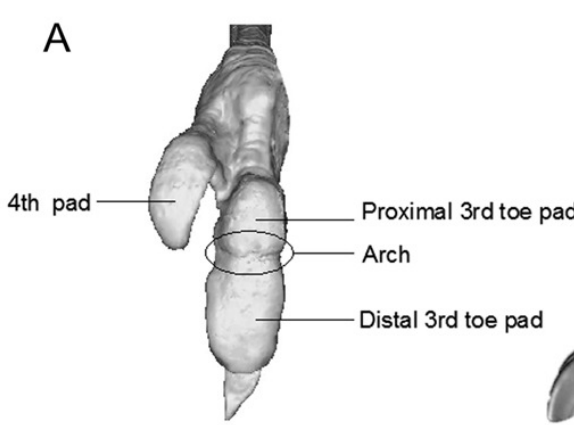

B

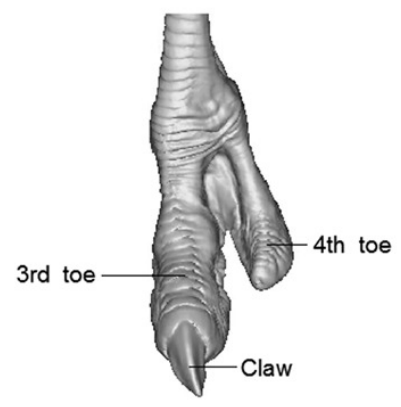

C

MTP
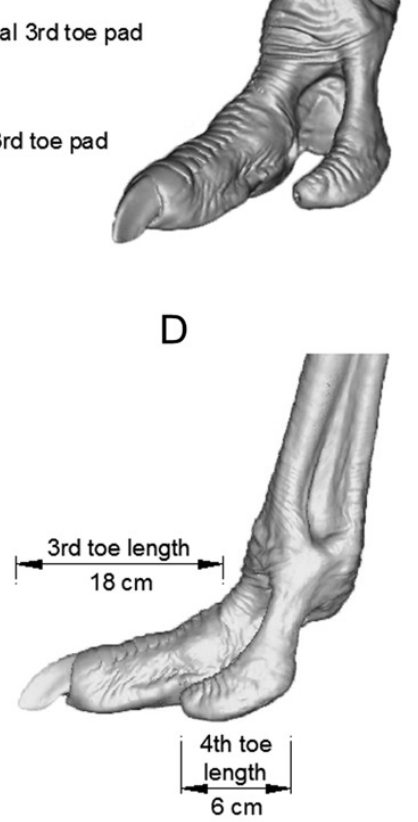

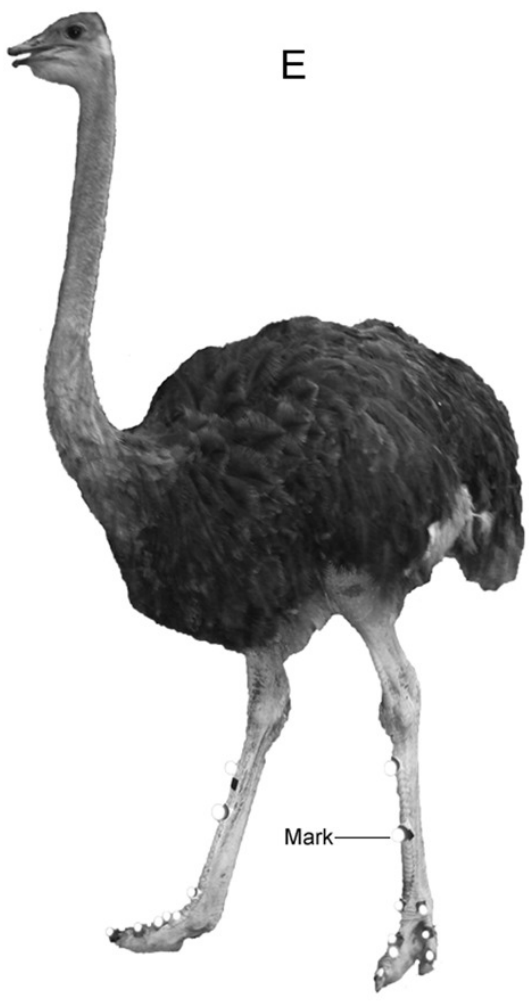

139

140

141

142

143

144

145

146

Fig. 2. Three-dimensional reconstruction of ostrich left foot and the model ostrich for trials. (A) ventral view; (B) front view; (C) isometric view; (D) lateral view; (E) the model ostrich for trials with marks on its legs.

3

\section{Trackway treatments}

An 80-m-long and 2-m-wide runway was constructed near the animal enclosure and fenced by 1.5-m-tall meshes (Fig. 3). All pebbles or sundries were removed. Within the runway, a trackway was narrowed to $1.4 \mathrm{~m}$ wide and $4 \mathrm{~m}$ long where the experimental equipment was installed. A 6-m-long and 4-m-wide sunshade net was set $3 \mathrm{~m}$ above the trackway to prevent any mistakes induced by sunlight spot in digital reconstruction. In solid ground trials, a customdesigned polycarbonate frame $\left(2 \times 1.5 \times 0.015 \mathrm{~m}^{3}\right)$ was made to fix the pressure plate. The encased pressure plate was placed on one level marble slab $\left(2 \times 1.4 \times 0.03 \mathrm{~m}^{3}\right)$ to avoid bending, and covered with a rubber sheet $\left(4 \times 1.4 \times 0.0025 \mathrm{~m}^{3}\right)$ to avoid potential damage. In loose sand trials, the trackway was prepared with a 4-cm-thick layer of loose and dry sand to simulate the living condition in farm and natural desert. The sand thickness was selected with some considerations. 
155 If the sand thickness was too large, the effect on plantar pressure would be much more blurry, 156 and the plantar pressure distributions were unclear or even more inaccurate. If the sand thickness 157 was too thin, the action of soft sands on ostrich foot would be ineffective. Therefore, the sand 158 thickness of $4 \mathrm{~cm}$ was selected to preliminarily study the plantar pressures of ostriches. The 159 pressure plate and its surrounding components were placed underground, and then the sands 160 were laid on the rubber sheet until the sand surface was leveled with the ground surface. The 161 particle size distribution of sands is shown in Fig. 4. Before each trial on loose sand, the sands 162 were prepared and the level conditions were confirmed to make sure the trackway was in the 163 same state.

164 In each trial, each ostrich ran (or walked) on the loose sand (or solid ground) for at least 165 three valid times, with more details shown in Table 1. The ostrich (1) walked on the solid ground, 166 (2) ran on the solid ground, (3) walked on the loose sand, or (4) ran on the loose sand. Running 167 and walking were classified as the velocity of $2.5-4.1$ and $0.7-1.7 \mathrm{~m} \cdot \mathrm{s}^{-1}$, respectively Ground 168 running was not studied in this study. 
A

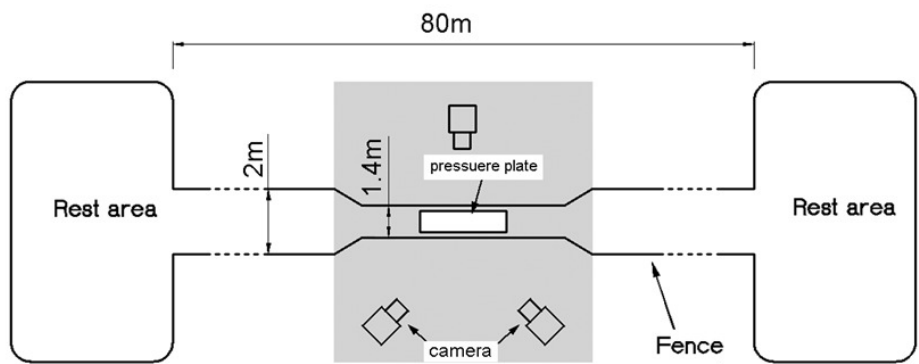

B

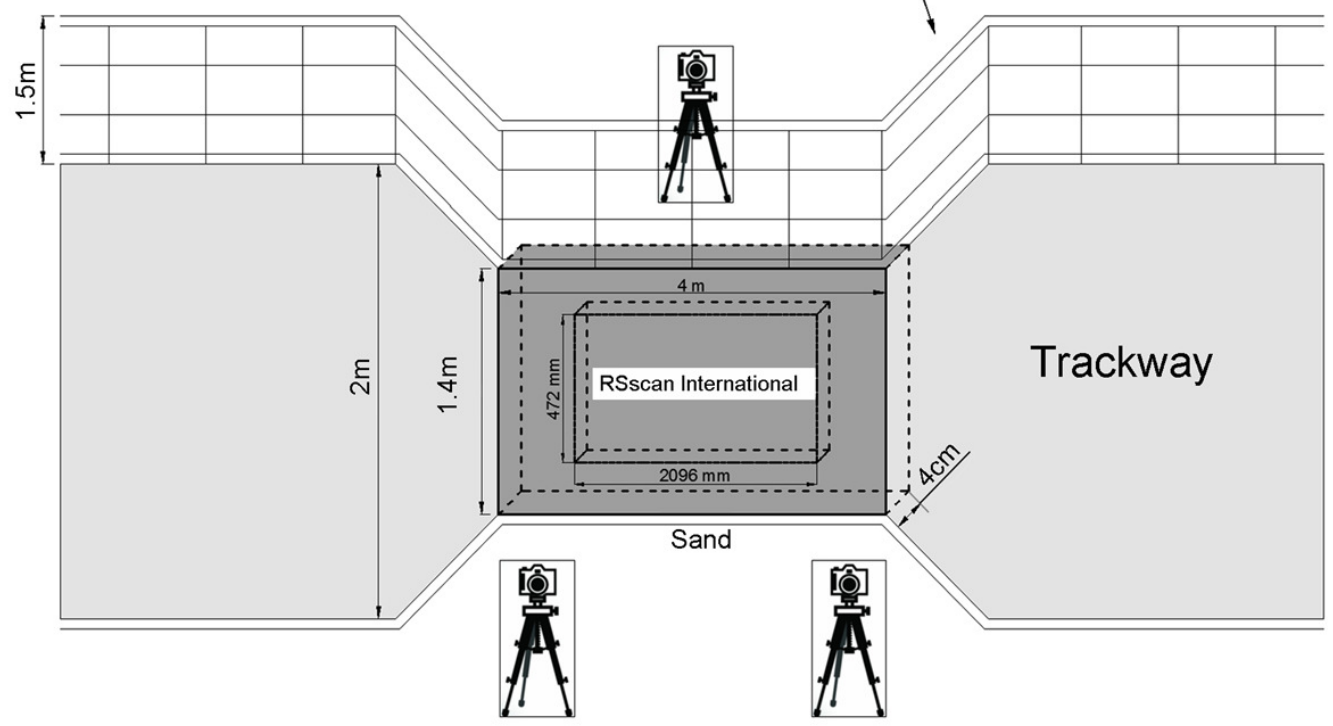

170

171 Fig. 3. Schematic of the trackway. (A) Top view; the shade was the data capturing area covered 172 with the sunshade net. (B) Experimental setup for capture of plantar pressure.

173

174 


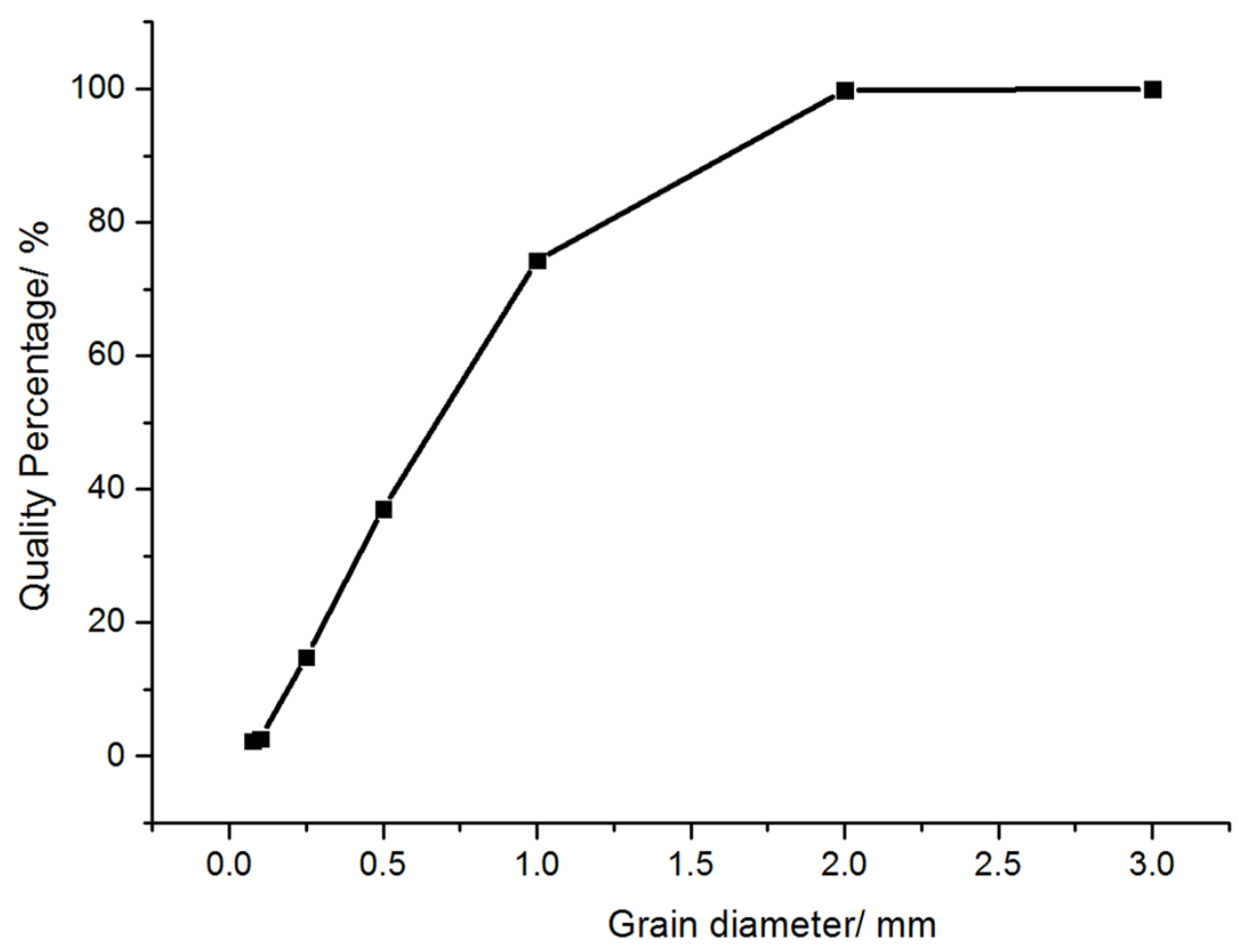

Fig. 4. Particle size distribution of sand used in trackway.

\section{Plantar pressure distribution and ground reaction forces}

Plantar pressure distribution and ground reaction forces were measured by an RSscan International $^{\circledR}$ pressure plate $\left(2096 \times 472 \mathrm{~mm}^{2}, 500 \mathrm{~Hz}\right.$ sampling, 16384 sensors with $0.5 \times 0.7$ $\mathrm{cm}^{2}$, USBII interface; Olen, Belgium). Data were acquired and analyzed on Footscan7 Gait 2nd generation $\left(\mathrm{RSscan}_{\text {International }}{ }^{\circledR}\right.$ ). Then we divided an ostrich foot into three functional parts: the 3rd toe (without claw), the 4th toe and the claw (Fig. 5) and investigated the effects of each part on locomotion. The ground reaction force of each plantar part was plotted and normalized against body weight. Total ground contact area, the ground contact area of each functional part, and the angle between the 3rd and 4th toes were determined on Footscan7 Gait based on Fig. 5. After the ostrich moved across the sand trackway, we photographed its footprints using an ordinary digital camera. After the surface of the pressure plate was covered with a 4-cm-thick layer of sand, the data of sample weights were inputted into the computer. Then the sample moved on the pressure plate to complete the calibration. The pressure plate was recalibrated after each trial. 


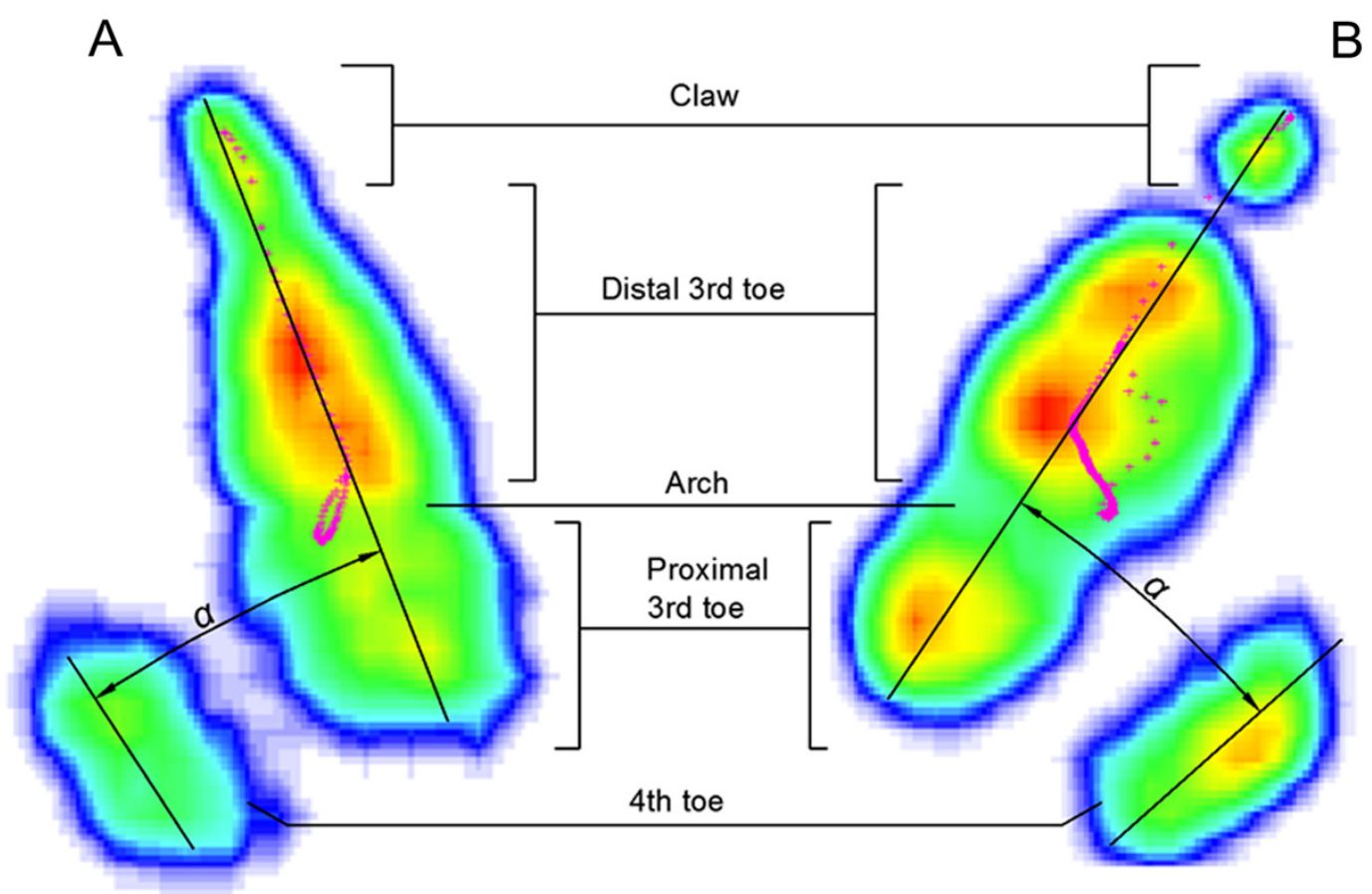
and solid ground (B). Claw, distal 3rd toe, arch, proximal 3rd toe and 4th toe corresponded to different foot parts. $\alpha$ was the angle between 3 rd toe and 4 th toe.

We used analysis of variance (ANOVA) to analyze the differences between two samples, and the effects of gait and media on plantar pressure. Under the condition of walking / running on solid ground / loose sand, we chose indicators of total peak pressure, peak pressure of 3rd toe, peak pressure of 4th toe and peak pressure of claw. Significance level was set at $\mathrm{P}<0.05$. The valid numbers of trials collected and of trials analyzed are shown in Table 1. 
Table 1. Tests of two samples under different media and gait modes

\section{Solid ground}

Loose sand

Walking Running Walking Running

Number of trials collected

Number of trials analyzed

10

10
17

10
6

6
11

6

205

206

\section{Results}

208

209

210

211

212

213

214

215

216

217

218

219

220

221

222

223

224

225

\section{Center of plantar pressure}

When the ostrich ran on the loose sand, the COP mostly originated from the middle of the 3rd toe (Fig. 6A). The 3rd toe was the first part to touch the loose sand (16 ms), followed immediately by the 4 th toe $(63 \mathrm{~ms})$ (Fig. $7 \mathrm{~A}$ ), so the COP trajectory moved towards the 4th toe. However, the key function of the 3rd toe was to bear the body weight, and an elliptical COP trajectory appeared in some trials at about the first half of the stance phase. The origin of COP indicates the middle of 3 rd toe was the first to touch the sand, followed immediately by the 4th toe. At the last half of the stance phase, COP moved from the middle of the 3rd toe directly to the claw, but the 4th toe gradually left the loose sand (158, 221 and 285 ms; Fig. 7A).

Different from the COP trajectory observed in the loose sand trials (Fig. 6A), a J-shaped COP trajectory was found in the solid-ground running trials (Fig. 6B). The areas of ground touching show the 3rd and 4th toes touched the ground simultaneously (16 and $63 \mathrm{~ms}$; Fig. 7B). Therefore, when an ostrich ran on the solid ground, the COP originated from the lateral part of the 3rd toe. During solid-ground running trials, COP followed a similar curve path that it moved from the lateral part to the longitudinal center of the distal 3rd toe, and then straightly to the claw after about $70 \%$ of the stance phase (Fig. 6B).

In most running trials, the course of COP traversed a longer distance and was closer to the arch on loose sand than on solid ground, which was because the arch contacted with the sand and 
A

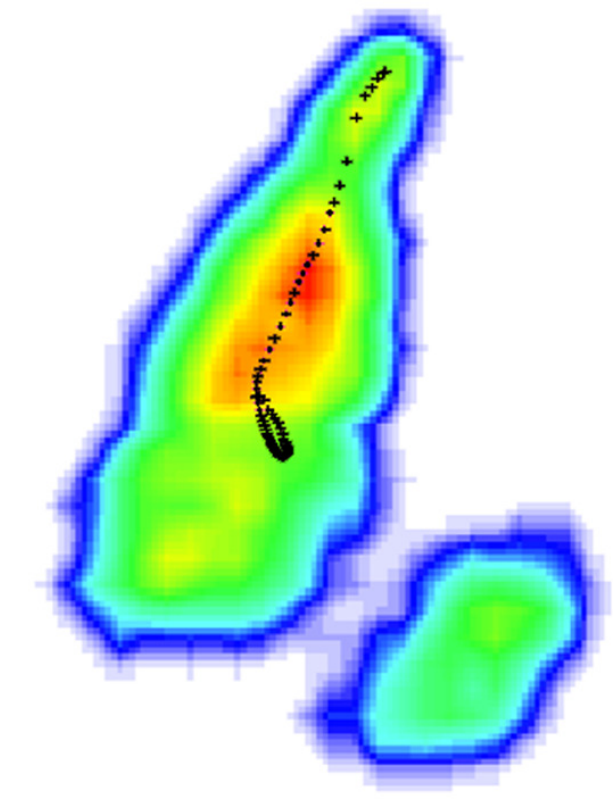

C

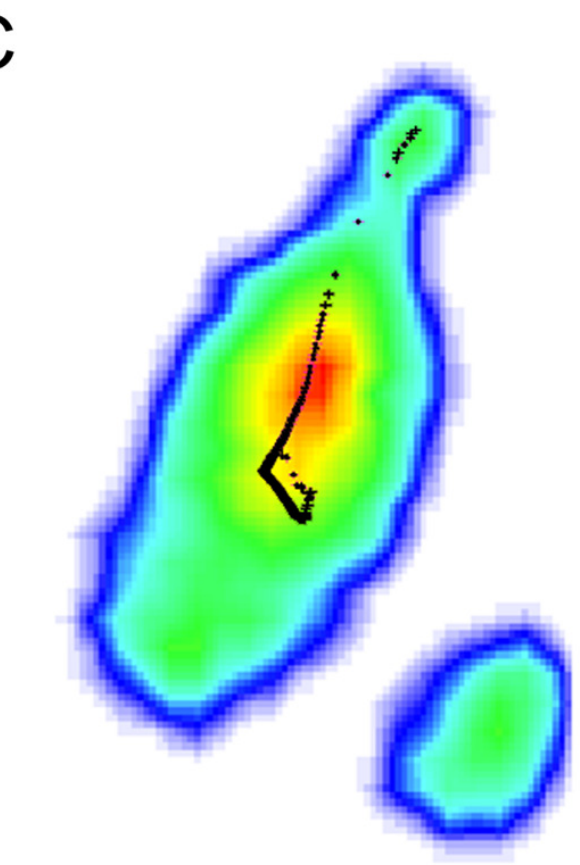

B
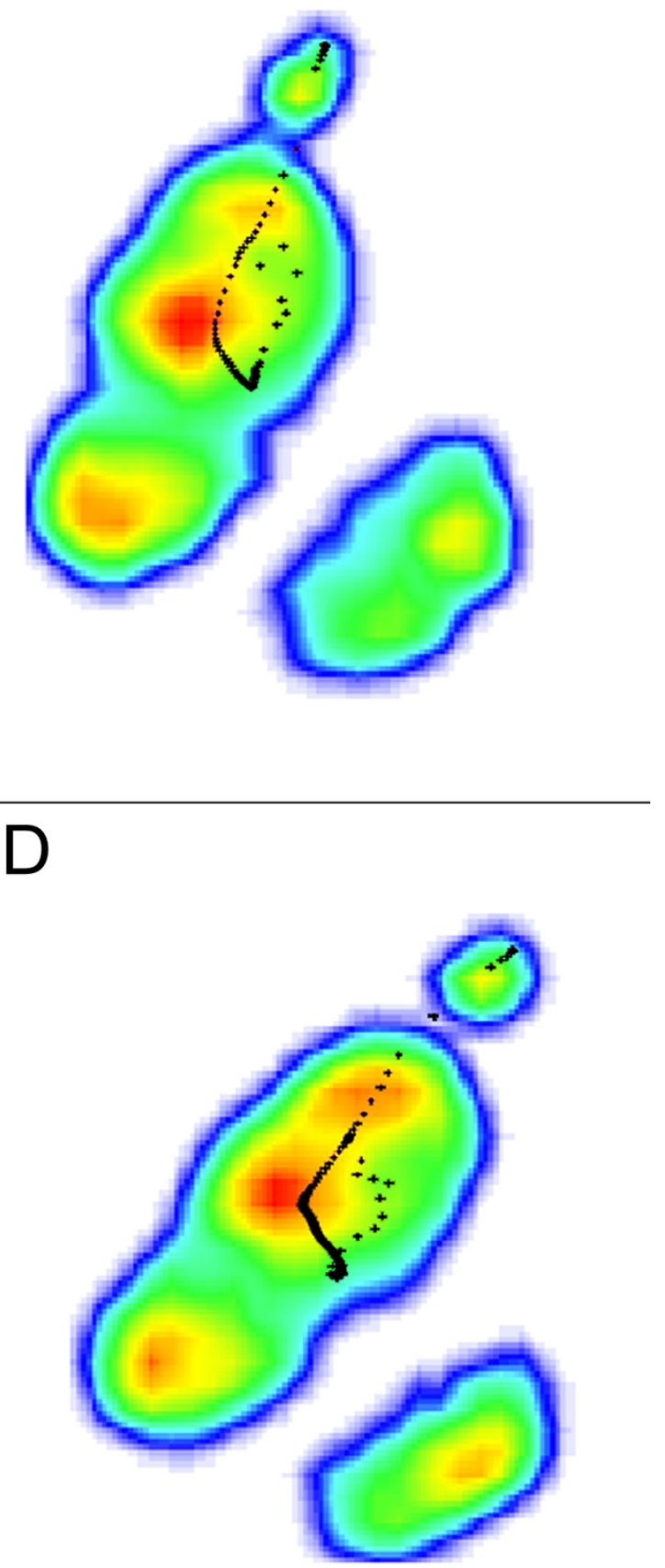

229 Fig. 6. Typical COP path (shown as black dots) of the ostrich right foot. (A) running on loose 
230

232

233

234

235

236

237

238

239

240

241

242

243

244

245

246

247

sand, (B) running on solid ground, (C) walking on loose sand, (D) walking on solid ground. Red, yellow, green and blue indicate the plantar pressure decreased gradually.

When the ostrich walked on loose sand or solid ground, the COP path originated from the similar position as that in the running trails. On the loose sand, the COP path was more changeable than the one on the solid ground (Fig. 6C). On solid ground, the distal 3rd toe and the 4th toe touched down almost simultaneously at the beginning of the stance phase (43 ms, Fig. $8 \mathrm{~B}$ ), which provided a stable landing and resulted in a high variable COP distribution at the initial $5 \%$ of the stance phase (Fig. 6D).

\section{Plantar pressure distribution and roll-off pattern}

Among all contact elements in the sand running trials, the 3rd toe was the first to touch down, followed by the 4th toe and the claw (Fig. 7A). During ground running trials, the 3rd toe was the first to touch the ground firs, followed by the claw almost immediately and finally the 4th toe (Fig. 7B). The sand walking trials involved the same roll-pattern as the sand running trials (Fig. 8A). During ground walking trials, the distal 3rd toe touched down at the beginning of stance phase, followed by the proximal 3rd toe and then the 4 th toe (Fig. 8B). 

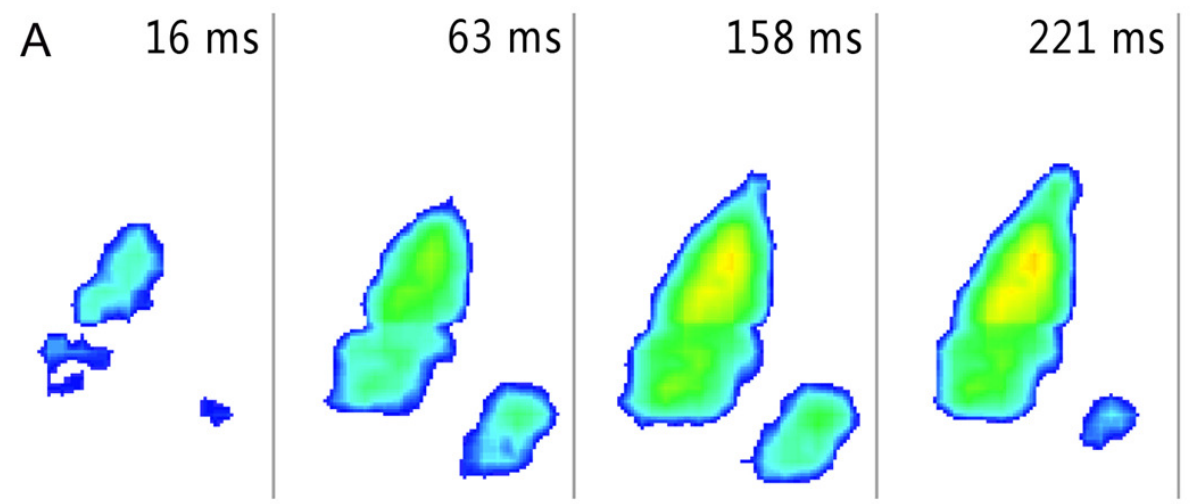

$285 \mathrm{~ms}$
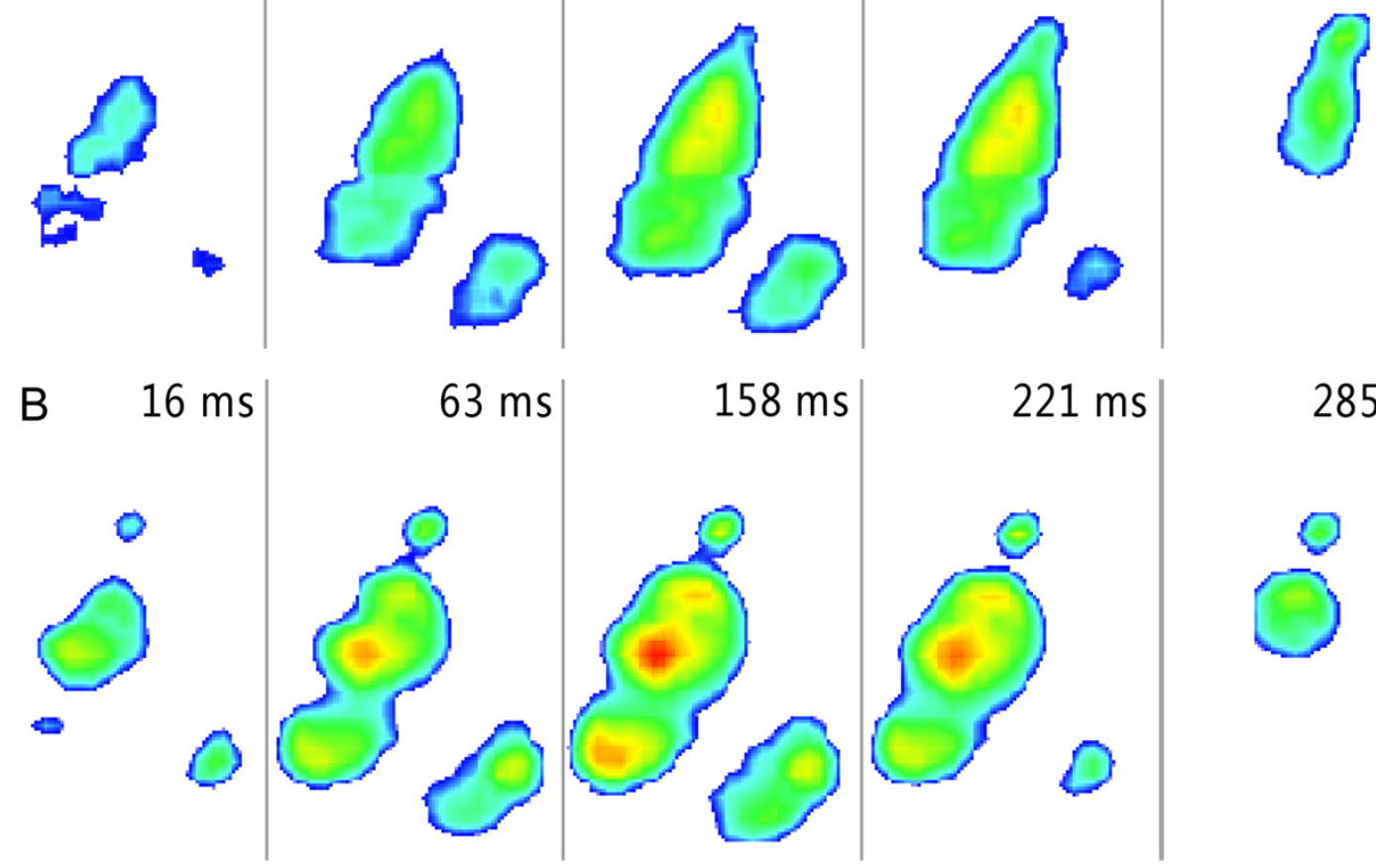

High
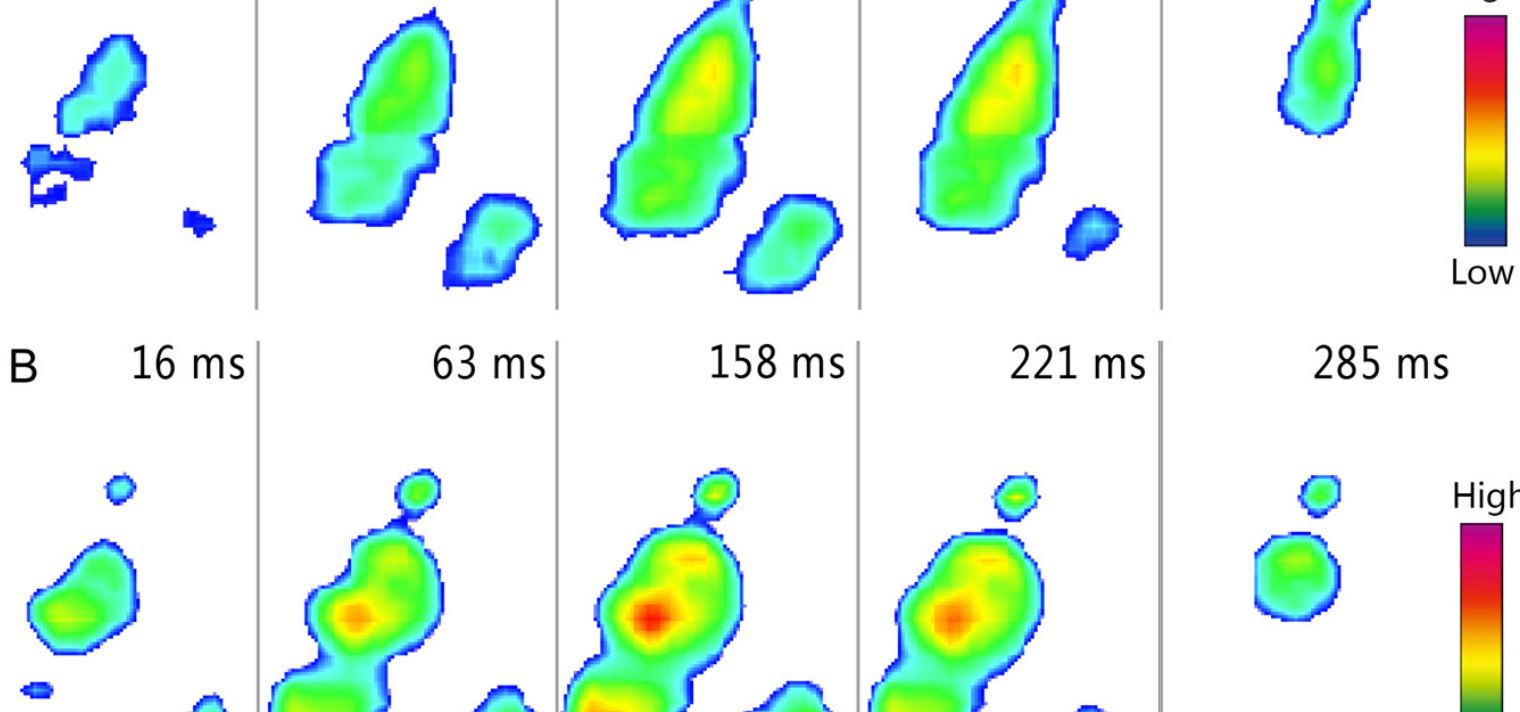

248

Fig. 7. Roll-off patterns of the right toe during loose sand (A) and solid ground (B) running trials. The images were recorded at 16, 63, 158, 221, and $285 \mathrm{~ms}$ after touch-down of foot. Loads were indicated on a gradient from red to dark blue (the same below). 


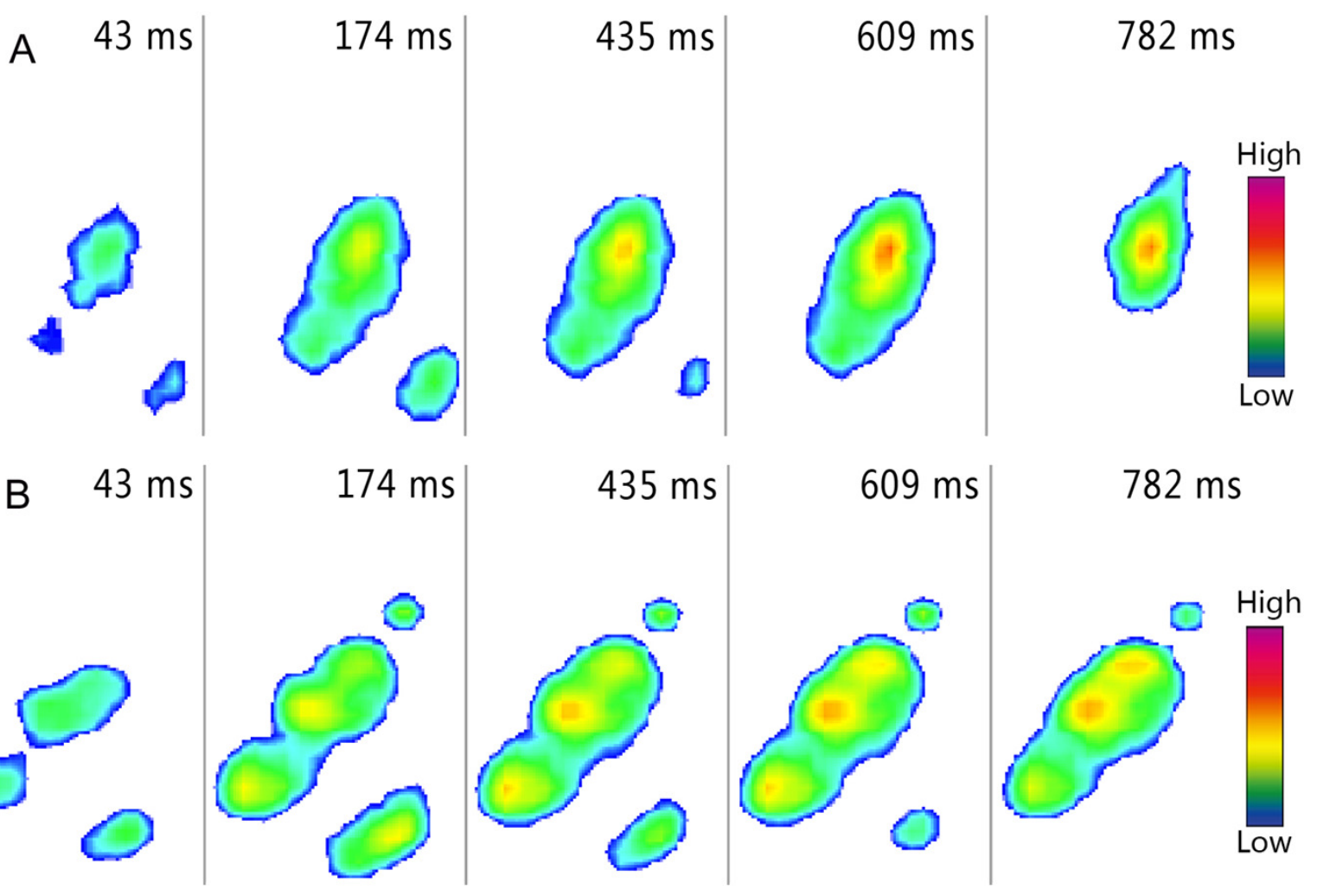

254

255

256

257

258

259

260

261

262

263

264

265

Fig.8. Roll-patterns of right toe during loose sand (A) and solid ground (B) walking trials.

The images were recorded at 43, 174, 435, 609 and $782 \mathrm{~ms}$ after touch-down of foot.

During sand running trials, a high-pressure region in the middle 3rd toe was observed around the initial contact region at the mid-stance, suggesting the distal 3rd toe bore the most load (Fig. 7A). At toe-off, the sands under the claw carried partial load, which resulted in connecting images between the claw and the distal 3rd toe. Except for a smaller pressure, the plantar pressure distribution of loose-sand walking (Fig. 8A) is the same as that in the running trials. The footprint examination in Fig. 9 supported the pressure distributions. The sand was solidified and flatted under the high-pressure region of the 3rd toe. Furthermore, two distinct sand bulges appeared on the sand surface under the compression of the arch and the claw. 

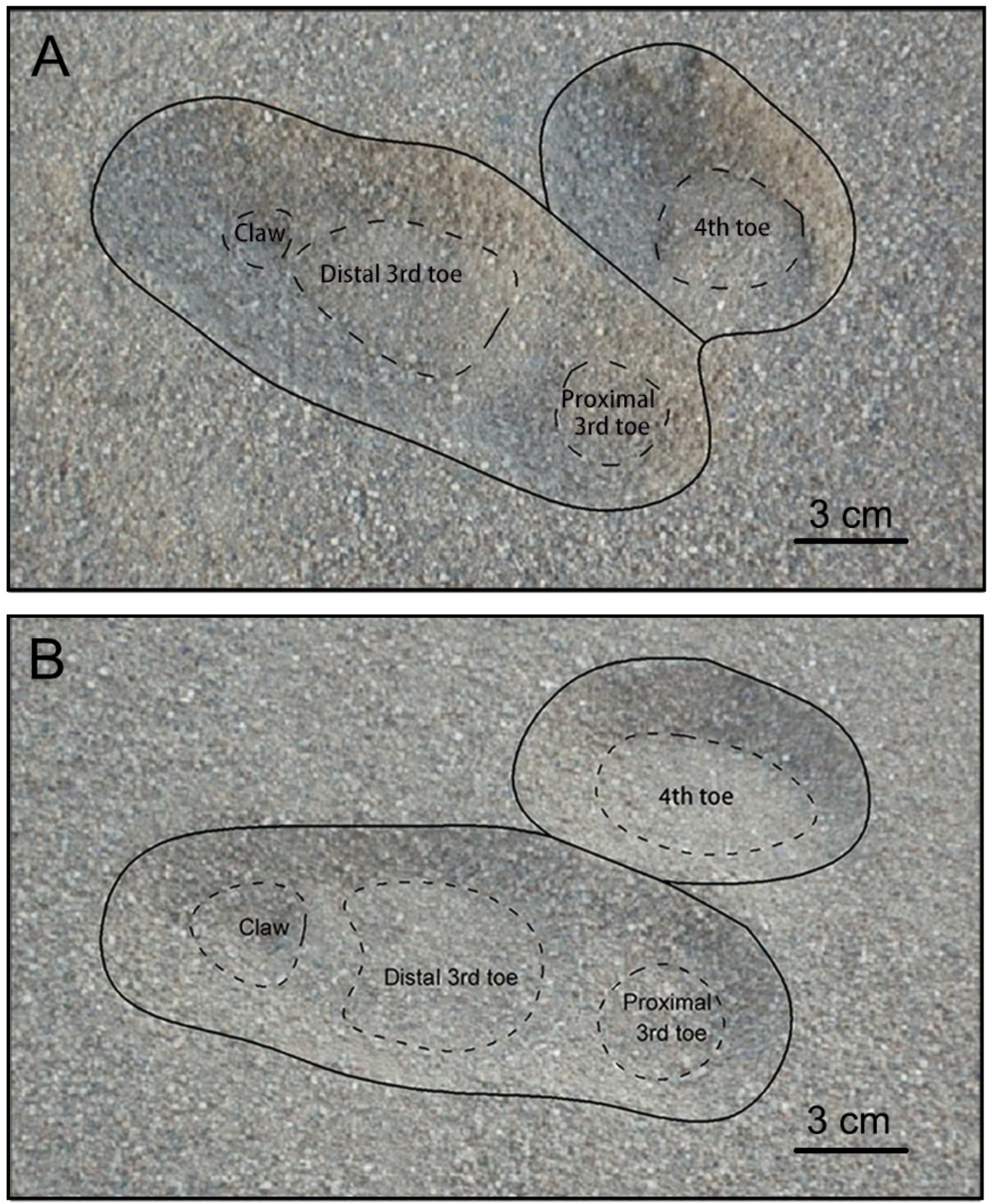

267 Fig. 9. Footprints of ostrich right foot when (A) running and (B) walking on loose sand. The 268 black solid lines show the region of disturbed sands. The dashed lines show the region of sand 269 solidified and flatted by different parts of ostrich foot. An obvious hump appeared between the 270 distal and proximal parts of the 3rd toe in both running and walking trials.

When the ostrich ran on solid ground, almost all parts of toes contacted the ground at the same time. As showed in Fig. 7B, three high-pressure areas on the 3rd toe and close to the digital 
274 joints were found after $20 \%$ of the stance phase. During walking trails, the dynamic pressure

275 distribution was consistent with that in running trials except for the lower pressure and the

276 exclusion of the claw from the initial contact period (Fig. 8B). Unlike on loose sand surface, the

277 arch of ostrich foot could be easily identified from the plantar pressure profiles when the ostrich 278 moved on the solid ground.

279 The surface areas on loose sand recorded by the pressure plate are shown in Table 2. 280 Clearly, the total pressure area and the pressure areas of main supported parts of ostrich toes are 281 slightly larger during running trails than walking trails. However, the areas of the claw were

282

283

284

285

286

287

288

289

290 about $52.7 \%$ larger and the angle awas $44.1 \%$ larger in running trials than in walking trials. When the trials were changed from ground walking to ground running, the load-bearing areas excluded the claw and $\alpha$ increased. The total surface area increased by $11.5 \%$ in running trails, which resulted from the $4.4 \%$ increase in the area of the 3rd toe and the $36 \%$ increase in the area of the 4th toe. In the loose sand trials, however, the area of the claw almost remained unchangeable when the bait was changed from walking to running. Total areas of toes on these two substrates suggest no obvious slip occurred, which was also supported by the qualitative analysis of videos and footprints.

Table 2. Plantar surface areas of total foot and functional parts

\begin{tabular}{cccccc}
\hline & $\begin{array}{c}\text { Total foot } \\
\left(\mathbf{c m}^{2}\right)\end{array}$ & $\begin{array}{c}\text { 3rd toe } \\
\left(\mathbf{c m}^{2}\right)\end{array}$ & $\begin{array}{c}\text { 4th toe } \\
\left(\mathbf{c m}^{2}\right)\end{array}$ & Claw $\left(\mathbf{c m}^{\mathbf{2}}\right)$ & $\boldsymbol{\alpha}\left(^{\circ}\right)$ \\
\hline Running on loose sand & $144.9 \pm 7.6$ & $89.9 \pm 4.8$ & $41.5 \pm 4.2$ & $11.3 \pm 3.5$ & $24.5 \pm 6.7$ \\
Walking on loose sand & $133.5 \pm 11.1$ & $89.6 \pm 5.5$ & $34.9 \pm 8.4$ & $7.4 \pm 2.7$ & $17.0 \pm 9.0$ \\
Running on solid ground & $159.8 \pm 4.5$ & $99.3 \pm 3.9$ & $48.4 \pm 3.1$ & $11.6 \pm 1.7$ & $20.3 \pm 3.1$ \\
Walking on solid ground & $143.3 \pm 6.5$ & $95.1 \pm 4.5$ & $35.6 \pm 5.1$ & $11.1 \pm 1.4$ & $19.6 \pm 4.9$ \\
\hline
\end{tabular}

291 Note:

292 Data are expressed as mean \pm standard deviation (the same below).

293

294 Ground reaction force in running trials 
295 The curves of total vertical ground reaction force were similar between different running 296 trials, with a sharp increase at the first half of the stance phase and a quick decrease at the second 297 half (Fig. 10A). The magnitudes of total ground reaction force on loose sand and solid ground 298 were over 2.5 and 1.8 times of body weight, respectively. Among all contact elements during 299 loose sand trials, the $3 \mathrm{rd}$ toe attained the maximum load at $50 \%$ of the stance phase (Fig. 10B), 300 while the 4 th toe reached the peak force at $35 \%$ of the stance phase and left the substrate at $69 \%$ 301 of the stance phase (Fig. 10C). The forces of the claw were detected at $8 \%$ of the stance phase, 302 increased to the peak at $80 \%$, and lasted to the end (Fig. 10D). 


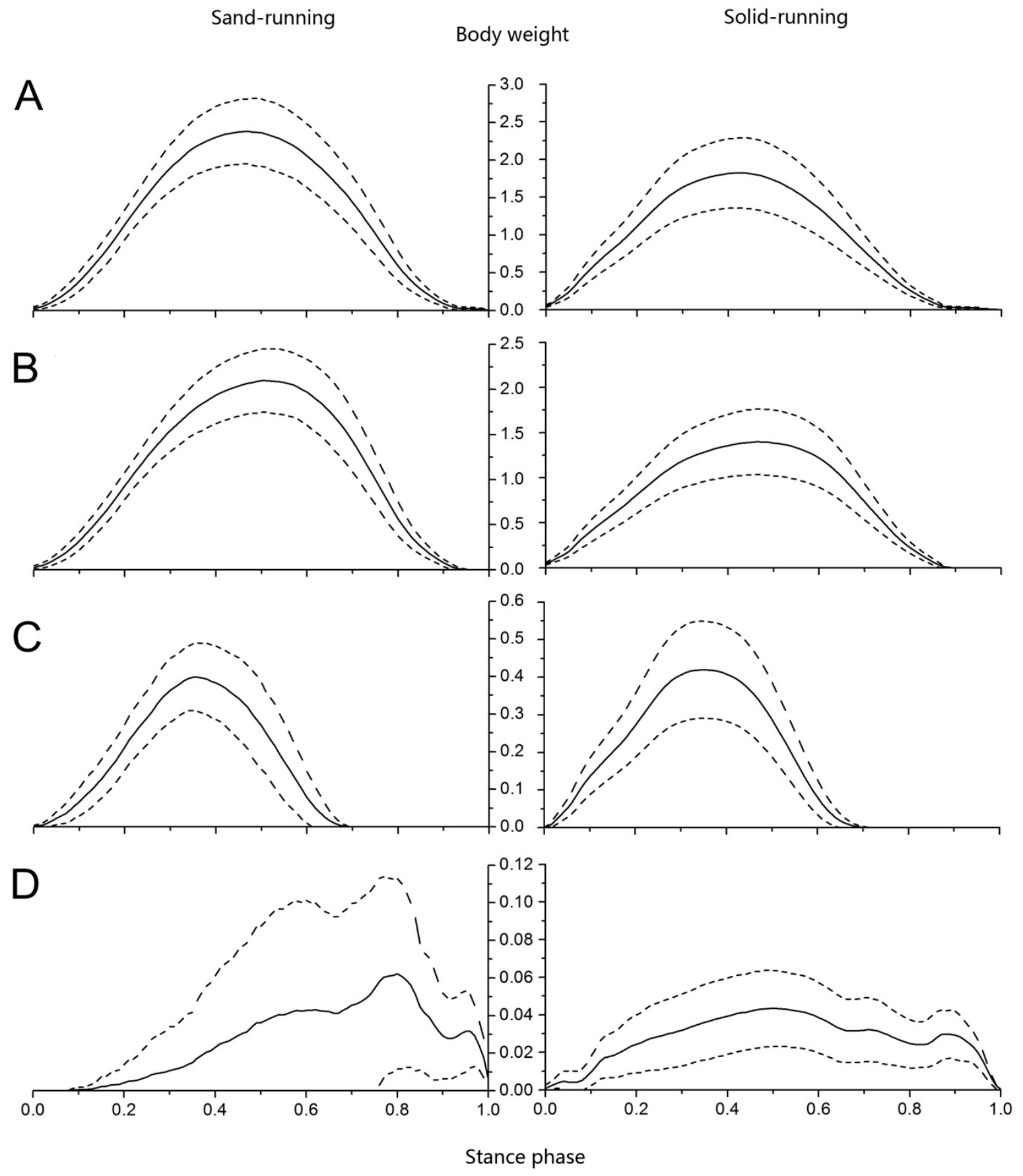

304

Fig.10. Vertical ground reaction forces versus stance phase during loose sand and solid ground running trials. Vertical ground reaction forces of (A) total foot, (B) 3rd toe, (C) 4th toe, and (D) the claw were all normalized against the body weight. The solid lines and dotted lines stand for the mean and standard deviations, respectively (the same below). 
310

The loads of contact elements increased simultaneously during solid ground running trials. Firstly, the maximum load on the 4 th toe was $34 \%$, and then it shifted to the 3 rd toe which attained the vertical peak force at $46 \%$ of the stance phase (Fig. 10). Generally, the 3rd toe bore the majority of load, with about $84 \%$ and $77 \%$ of the entire load during sand and ground trials, respectively, while the 4 th toe carried only about $14 \%$ and $23 \%$ of the entire load during sand and ground trials, respectively. Although the curves of ground reaction forces of total foot, 4th and 3rd toes were all similar between substrates, the curve of the claw was obviously different, as the standard deviations under the claw were larger on sand surface than on solid surface. At toe-off, the vertical peak force shared by the claw was $1.5 \%$ and $2.4 \%$ of the entire load on loose sand and solid ground, respectively.

\section{Ground reaction force in walking trials}

The profiles of total vertical ground reaction forces in walking trials were slightly different from those recorded in running trails. The profiles in walking trials could be roughly divided into three parts: (1) a quick rise at $20 \%$ of the stance phase, (2) a slight increase at $50 \%$ of the stance phase, and (3) a rapid drop after about $70 \%$ of the stance phase (Fig. 11). The maximum total ground reaction forces on loose sand and solid ground were 1.3 and 1.1 times of the body weight, respectively, which occurred at $73 \%$ and $63 \%$ of the stance phase, respectively (Fig. 11A). In walking trials, the 4 th toe, the 3 rd toe and the claw successively attained the peak vertical ground reaction force. During the sand and ground walking trials, the vertical peak forces under the 4th toe were $10.7 \%$ and $22.8 \%$ of the vertical total forces respectively, and the contact durations between the 4 th toe and the substrate were at $76 \%$ and $94 \%$ of the stance phase, respectively (Fig. 11C). 
Sand-walking

A

B

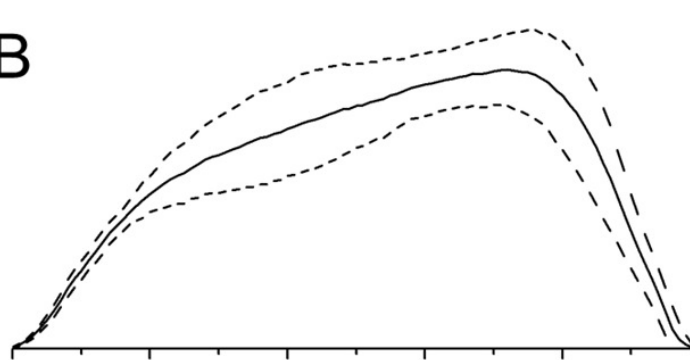

C
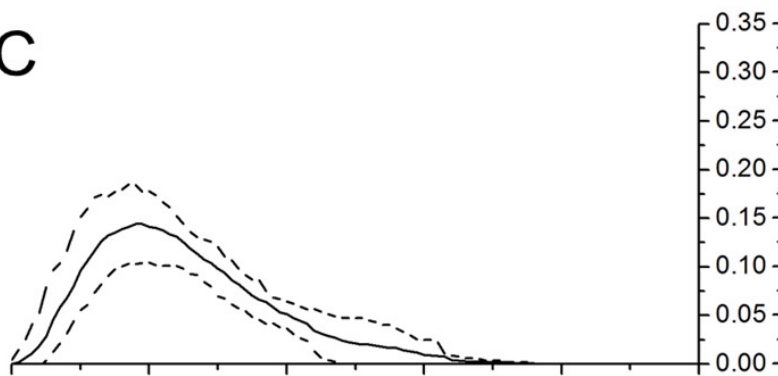

D

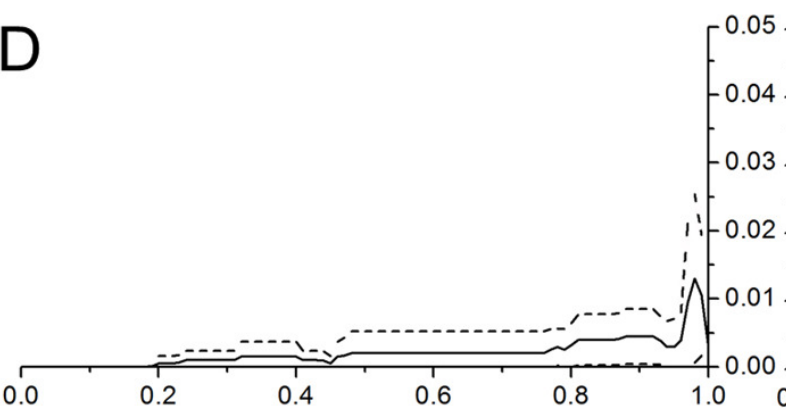

Stance phase
Solid-walking

Body weight 
338

339

340

341

342

343

344

Table 3. Peak plantar pressures of two samples in different media and gaits

To analyze whether differences existed between two samples, we selected the peak pressures of different functional parts as indices. The differences in different media and different gaits between two samples were tested via one-way ANOVA. As shown in Table 3, no significant difference was found between the two samples (all $\mathrm{p}>0.05$ ), so the data of two samples were combined to analyze the significance of the gaits and the media.
Loose sand

\begin{tabular}{|c|c|c|c|c|c|}
\hline & \multirow[b]{2}{*}{ Sample } & \multicolumn{2}{|c|}{ Solid ground } & \multicolumn{2}{|c|}{ Loose sand } \\
\hline & & Walking & Running & Walking & Running \\
\hline \multirow{2}{*}{ Total } & 1 & $1.13 \pm 0.290$ & $2.14 \pm 0.540$ & $1.49 \pm 0.200$ & $2.55 \pm 0.560$ \\
\hline & 2 & $1.12 \pm 0.270$ & $1.87 \pm 0.390$ & $1.34 \pm 0.160$ & $3.01 \pm 0.810$ \\
\hline \multirow{2}{*}{ 3rd toe } & 1 & $1.05 \pm 0.300$ & $1.64 \pm 0.400$ & $1.48 \pm 0.110$ & $2.17 \pm 0.510$ \\
\hline & 2 & $0.99 \pm 0.270$ & $1.39 \pm 0.320$ & $1.34 \pm 0.160$ & $2.34 \pm 0.090$ \\
\hline \multirow{2}{*}{ 4th toe } & 1 & $0.24 \pm 0.030$ & $0.48 \pm 0.150$ & $0.15 \pm 0.025$ & $0.4 \pm 0.130$ \\
\hline & 2 & $0.28 \pm 0.055$ & $0.47 \pm 0.095$ & $0.15 \pm 0.053$ & $0.4 \pm 0.060$ \\
\hline \multirow{2}{*}{ Claw } & 1 & $0.041 \pm 0.006$ & $0.047 \pm 0.030$ & $0.014 \pm 0.003$ & $0.02 \pm 0.010$ \\
\hline & 2 & $0.032 \pm 0.018$ & $0.047 \pm 0.020$ & $0.016 \pm 0.016$ & $0.04 \pm 0.020$ \\
\hline \multicolumn{6}{|l|}{ Note: } \\
\hline \multicolumn{6}{|c|}{ No significant inter-individual effects were found at $\mathrm{p}<0.05$. } \\
\hline \multicolumn{6}{|c|}{ The values were all normalized against the body weight. } \\
\hline
\end{tabular}

\begin{tabular}{|c|c|c|c|c|c|}
\hline & \multirow[b]{2}{*}{ Sample } & \multicolumn{2}{|c|}{ Solid ground } & \multicolumn{2}{|c|}{ Loose sand } \\
\hline & & Walking & Running & Walking & Running \\
\hline \multirow{2}{*}{ Total } & 1 & $1.13 \pm 0.290$ & $2.14 \pm 0.540$ & $1.49 \pm 0.200$ & $2.55 \pm 0.560$ \\
\hline & 2 & $1.12 \pm 0.270$ & $1.87 \pm 0.390$ & $1.34 \pm 0.160$ & $3.01 \pm 0.810$ \\
\hline \multirow{2}{*}{ 3rd toe } & 1 & $1.05 \pm 0.300$ & $1.64 \pm 0.400$ & $1.48 \pm 0.110$ & $2.17 \pm 0.510$ \\
\hline & 2 & $0.99 \pm 0.270$ & $1.39 \pm 0.320$ & $1.34 \pm 0.160$ & $2.34 \pm 0.090$ \\
\hline \multirow{2}{*}{ 4th toe } & 1 & $0.24 \pm 0.030$ & $0.48 \pm 0.150$ & $0.15 \pm 0.025$ & $0.4 \pm 0.130$ \\
\hline & 2 & $0.28 \pm 0.055$ & $0.47 \pm 0.095$ & $0.15 \pm 0.053$ & $0.4 \pm 0.060$ \\
\hline \multirow{2}{*}{ Claw } & 1 & $0.041 \pm 0.006$ & $0.047 \pm 0.030$ & $0.014 \pm 0.003$ & $0.02 \pm 0.010$ \\
\hline & 2 & $0.032 \pm 0.018$ & $0.047 \pm 0.020$ & $0.016 \pm 0.016$ & $0.04 \pm 0.020$ \\
\hline \multicolumn{6}{|l|}{ Note: } \\
\hline \multicolumn{6}{|c|}{ No significant inter-individual effects were found at $\mathrm{p}<0.05$. } \\
\hline \multicolumn{6}{|c|}{ The values were all normalized against the body weight. } \\
\hline
\end{tabular}

Note:

No significant inter-individual effects were found at $\mathrm{p}<0.05$.

The values were all normalized against the body weight.

348

Two factors were analyzed: gait mode (walking vs. running) and media (solid ground vs. 350 
351 effects of gait mode and media were analyzed for each part (total, 3rd toe, 4th toe and claw), and 352 illustrated in terms of $F$ value and $p$ value (Table 4).

Table 4. F value and $p$ value with consideration of interaction

\begin{tabular}{ccccccc}
\hline & \multicolumn{2}{c}{ Media } & \multicolumn{2}{c}{ Gait mode } & \multicolumn{2}{c}{ Interaction } \\
\cline { 2 - 6 } & F value & P value & F value & P value & F value & P value \\
\hline Total & 11.87 & 0.0018 & 52.7 & $6.65 \times 10^{-8}$ & 2.49 & 0.12 \\
3rd toe & 25.49 & $2.42 \times 10^{-5}$ & 36.89 & $1.5 \times 10^{-6}$ & 2.47 & 0.12 \\
4th toe & 8.78 & 0.0061 & 58.71 & $2.39 \times 10^{-8}$ & 0.42 & 0.51 \\
Claw & 7.84 & 0.0091 & 4.57 & 0.041 & 0.27 & 0.6 \\
\hline
\end{tabular}

As showed in Table 4, media and gait mode are significant independent factors, but their interaction is not significant. Thus, it can be stated the main effects of both media and gait modes are significant, but the effect on the outcome of the change in gait mode does not depend on the media. To further detect their interaction, we drew interaction plots (Fig. 12). 

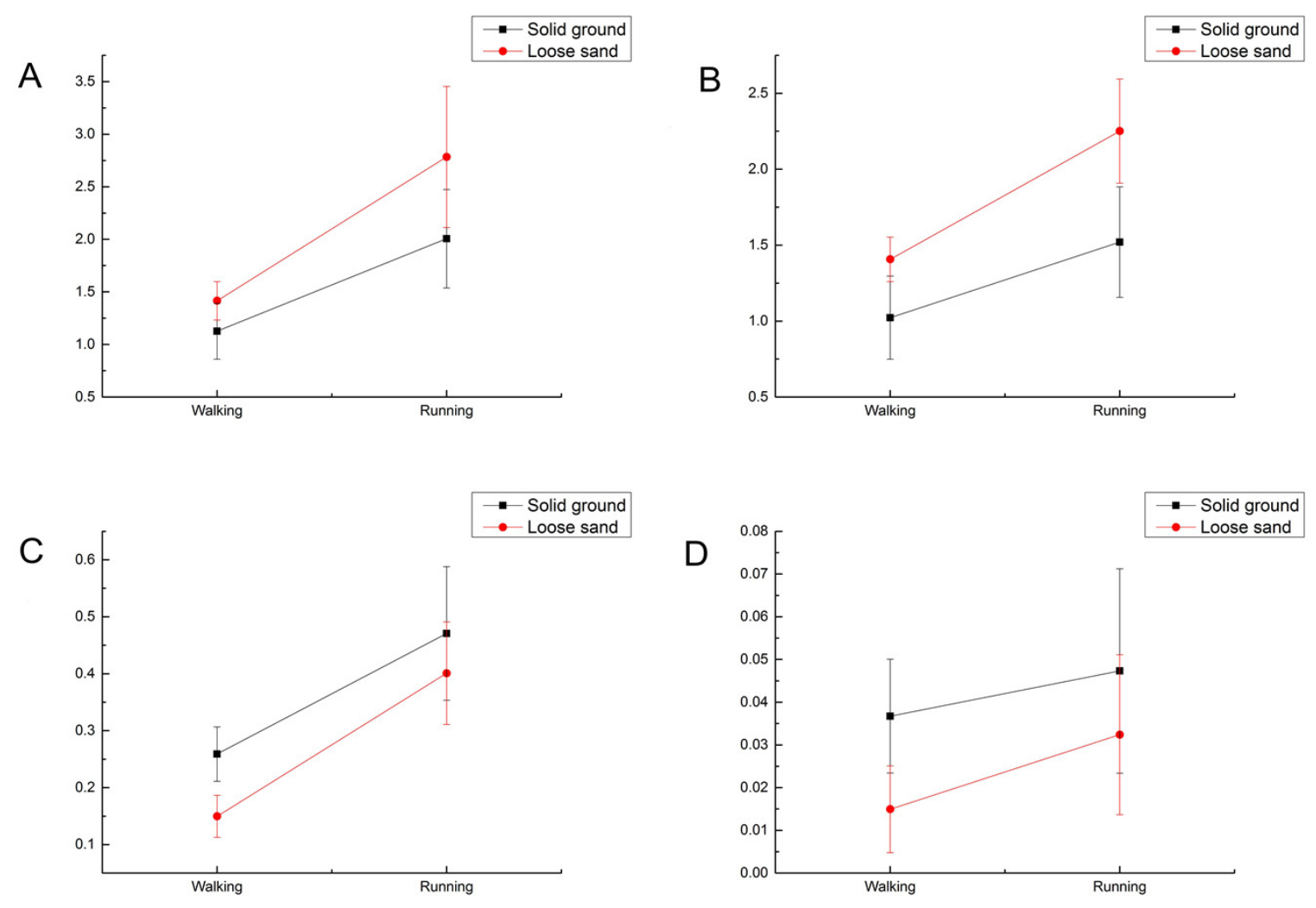

Fig. 12. Peak plantar pressures under different media and gaits. (A)Total force, (B)3rd toe, (C)4th toe, (D)Claw. The values were all normalized against the body weight.

The population means of media and gaits were all significantly different $(\mathrm{p}<0.05)$. we recalculated the effects of the two factors without interaction.

Table 5. F value and $\mathrm{p}$ value without consideration of interaction 


\begin{tabular}{ccccc}
\hline Total & 11.29 & 0.0021 & 47.81 & $1.34 \times 10^{-7}$ \\
3rd toe & 24.25 & $3.12 \times 10^{-5}$ & 32.75 & $3.41 \times 10^{-6}$ \\
4th toe & 8.96 & 0.0055 & 61.2 & $1.25 \times 10^{-8}$ \\
Claw & 8.04 & 0.0082 & 4.4 & 0.044 \\
\hline
\end{tabular}

369

370

371

372

373

374

375

376

377

378

379

380

381

382

383

384

385

386

387

388

389

390

391

The population means of media and gait mode were still significantly different without consideration of interaction $(\mathrm{p}<0.05$; Table 5$)$.

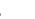

\section{Discussion}

The dynamic pressure distribution and the COP path during solid ground running or walking trials are consistent with a previous study [32]. This consistency in the profiles of ground reaction forces suggests the 3rd toe supports most loads and the 4th helps to maintain body balance. However, there are some differences in the COP path and the magnitude of ground reaction forces between the two studies, which should result from the differences in the collected velocities. Furthermore, our study is unique that we identified three high- pressure regions under the digital joints of the 3rd toe, which suggest the relation between the ground reaction force and the plantar skeleton, as well as the importance of digital cushion in protecting the plantar skeleton and soft tissues.

\section{Locomotion on loose sand}

During loose-sand running, the touchdown of the 3rd toe resulted in a larger heel contact area and a smaller attack angle, compared with solid ground locomotion. The attack angle is between the cross-sectional plane of the 3rd toe and the sand surface. As reported, the vertical reaction force of intruding into granular materials $\left(F_{z}\right)$ can be computed as follows [3]:

$$
\mathrm{F}_{\mathrm{z}}=\delta \times \mathrm{A} \times \mathrm{Z}
$$

where $\delta$ is the vertical stresses per unit depth, $A$ is the projected intruder surface area, and $Z$ is the intrusive depth. For a given granular material, $\delta$ depends on the orientation and moving direction of the intruder. Although the relationship between $\delta$ and the intruder behavior is complicated, it 
392 is clear a smaller attack angle would increase the reaction force [3]. Thus, the ostrich toe 393 orientation with a smaller attack angle during touchdown on loose sand could generate a stronger 394 reaction force to support its body load. The phalanxes of the 3rd toe left the ground in order, 395 which resulted in a smaller $Z$. An additional force, which was derived from the arch of the 3rd 396 toe, not only enlarged the contact surface but also solidified the sands under the 3rd toe.

397 During push-off, the 3rd toe did not slip on sand, but the claw continued to intrude into sand. 398 This phenomenon differed from the foot kinematics of zebra-tailed lizard moving on sand, in 399 which the feet paddled through granular materials, generating force with huge energy loss $[2,43]$. 400 The no-slip movement of ostrich toes and claw could be explained by the mechanism of granular 401 material solidification. This mechanism was revealed by the locomotion of sea turtles on 402 granular surfaces, in which the sea turtles created a hard sand region behind its flippers that 403 remained no-slip locomotion [22]. Hence, we estimated the reaction force for advancing 404 locomotion was partly supplied by the solid properties of sands under the toes. Furthermore, our experiments indicate the maximum friction coefficient of a plate could reach 0.65 before slipping during moving on granular medium [33]. Therefore, the combination of the no-slip toes and the dense papillae covered on plantar surface may lead to acceleration because of considerable friction.

Our investigation suggests the 4th toe could correct the possible imbalance of the center of body weight on solid ground. Compared to the 3rd toe, the 4th toe shares less loads during the locomotion (particularly walking) on loose sand, which might result from the compensation of balance provided by the 3rd toe with its elliptical morphology. When the 3rd toe is intruding into loose sand, the lateral part could utilize the reaction of sand particles by compressing the sands to reduce the load of the 4 th toe [16].

\section{5}

\section{Locomotion on solid ground}

Repeated transient loading of foot strike, which occurred when the foot touched the ground and then transmitted upward the skeleton and soft tissues, might cause fatigue damage and accelerate running injuries $[34,35]$. However, to eliminate the disadvantage of foot strike, the ostrich utilized a special strategy in long-distance running, which had been revealed by human kinematics examination. Abundant evidences show the habitually barefoot endurance runners as well as the running endurance Homo erectus landed on ground with the lateral foreparts of their feet, so as to avoid the transient forces $[36,37]$. These discrete points of the initial COP, located on the lateral distal part of the 3rd toe, indicate the ostrich landed on the ground with the lateral 
424

425

426

427

428

429

430

431

8

foreparts of the 3rd toe. During the impact process, the metatarsophalangeal joint flexed and the phalangeal joints extended as the toe moved under the control of tendons and muscles [28].

By flexing and extending these joints, ostrich toes partly translated the translational kinetic energy into the rotational kinetic energy of joints, which reduced the effective mass involved in the initial foot-ground contact phase and further decreased the magnitude of the impact transient force $[36,38]$.

It has been suggested a part of foot strike is absorbed by the viscoelastic material located in the interface between the digital phalanx and the ground, especially the adipose cushion [39]. The viscoelastic material in ostrich footpad includes the adipose cushion, which consists of numerous adipocytes, a few other connective tissues, and abundant parallel collagen fibers [31]. Shock absorption of the viscoelastic material in ostrich footpad was brought by the deformation of fat cells and collagen fibers against the compression. Further studies on the mechanical property of the adipose cushion pad may help to comprehensively understand how the ostrich footpads save energy and reduce the magnitude of transient force [40].

.

0

\footnotetext{
Slight errors existed between the plantar pressure and the measured value in the loose sand, which were mainly due to the rolling and sliding of sand particles, and the extrusion and collision between sand particles. However, there is no proper test technology for measurement of large animal plantar pressures, when the large animal running or walking on loose sands. We laid 4-cm-thick sand on the pressure plate and tested the plantar pressure could be tested when an ostrich walked or ran on loose sand. Despite some errors in the quantitative measurement of ostrich plantar pressure, this method could be used to analyze the changing rules of ostrich plantar pressure and its proportion in different plantar parts when the ostrich was travelling on sand. Compared with the change rules of ostrich plantar pressure on solid ground, the high efficiency mechanism of ostrich foot travelling on sand could be studied. In the future, we will continue to study the effects of sand thickness on ostrich plantar pressure during sand travelling, and explore the method to accurately measure ostrich plantar pressure in sandy environment.
} 


\title{
Conclusions
}

455

456

457

The COP trajectory originated from the center of the 3rd toe when the ostrich ran on loose sand, which was different from the J-shape COP trajectory found on solid ground. The COP trajectory combined with the pressure distribution of each functional part and the motion of toes, indicating ostrich toes did not play the same functions on different substrates. On loose sand, the enlarged 3rd toe carried more body loads and provided sufficient traction by using the sandsolidification characteristics. The special arch and the well-developed claw of the 3rd toe also played a crucial role during locomotion on loose sand. On solid ground, the lateral part of the 3rd toe touched the ground in the beginning of stance phase, which prevented the skeletal system and soft tissues from harmful collision. On both substrates, the cushion pads of ostrich toes not only absorbed collision but also provided additional area to decrease pressure by deforming, especially at high speed. The morphology of toe improved the effect of traction and helped to maintain the balance of COM on sand surface.

7

8

9

\section{Supplemental Information}

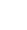

Analysis of ostrich running on loose sand. Raw data for plantar pressure on different parts
of ostrich foot (claw, 3 rd toe, 4th toe and total). Fig. 10 sand-running was plotted from these dots. of ostrich foot (claw, 3rd toe, 4th toe and total). Fig. 10 sand-running was plotted from these dots.

4

\begin{abstract}
different parts of ostrich foot (claw, 3rd toe, 4th toe and total). Fig.10 solid-running was plotted
\end{abstract} from these dots.

Analysis of ostrich running on solid ground. Raw data for the plantar pressure on

8

Analysis of ostrich walking on loose sand. Raw data for the plantar pressure on different parts of ostrich foot (claw, 3rd toe, 4th toe and total). Fig.11 sand-walking was plotted from these dots. 
Analysis of ostrich walking on solid ground. Raw data for the plantar pressure on different parts of ostrich foot (claw, 3rd toe, 4th toe and total). Fig.11 solid-walking was plotted 485 from these dots.

486

Video of ostrich running on loose sand.

488

489

Video of ostrich running on solid ground.

490

491

Video of ostrich walking on loose sand.

492

493

Video of ostrich walking on solid ground.

494

495

496

Reference

497

498

499

500

501

502

503

504

505

506

1. Dickinson MH, Farley CT, Full RJ, Koehl MAR, Kram R, Lehman S. (2000) How animals move: an integrative view. Science 288: 100-106. doi: 10.1126/science.288.5463.100

2. Li C, Hsieh,T. and Goldman DI. (2012) Multi-functional foot use during running in the zebra-tailed lizard (Callisaurus draconoides). J Exp Biol215: 3293-3308. doi: $10.1242 /$ jeb.061937

3. Li C, Zhang T, Goldman DI. (2013) A terradynamics of legged locomotion on granular media. Science 339: 1408-1412. doi: 10.1126/science.1229163

4. Cavagna GA, Kaneko M. (1977) Mechanical work and efficiency in level walking and running. J Physiol 268: 467-481. doi:10.1113/jphysiol.1977.sp011866

5. Alexander RM. (1991) Energy-saving mechanisms in walking and running. J Exp Biol 160: 
507

55-69.

6. Cavagna GA, Willems PA, Legramandi MA, Heglund NC. (2002) Pendular energy transduction within the step in human walking.J Exp Biol 205: 3413-3422.

7. Spence AJ, Revzen S, Seipel J, Mullens C, Full RJ. (2010) Insects running on elastic surfaces. J Exp Biol213: 1907-1920. doi: 10.1242/jeb.042515

8. Geyer H, Seyfarth A, Blickhan, R. (2005) Spring-mass running: simple approximate solution and application to gait stability. J THEOR BIOL 232: 315-328. doi: 10.1016/j.jtbi.2004.08.015

9. Birn-Jeffery AV, Hubicki CM, Blum Y, Renjewski D, Hurst JW, Daley MA. (2014) Don't break a leg: running birds from quail to ostrich prioritise leg safety and economy on uneven terrain. J Exp Biol 217: 3786-3796. doi: 10.1242/jeb.102640

10. Geyer H, Seyfarth A, Blickhan R. (2006) Compliant leg behaviour explains basic dynamics of walking and running. Proc R Soc B 273: 2861-2867. doi: 10.1098/rspb.2006.3637

11. Full RJ, Tu MS. (1990) Mechanics of six-legged runners. J Exp Biol 148: 129-146.

12. Heglund NC, Fedak MA, Taylor CR, Gavagna GA. (1982) Energetic and mechanics of terrestrial locomotion. IV. Total mechanical energy changes as a function of speed and body size in birds and mammals.J Exp Biol 97: 57-66.

13. Collins S, Ruina A, Tedrake R, Wisse M. (2005) Efficient bipedal robots based on passivedynamic walkers. Science 307: 1082-1085. doi: 10.1126/science.1107799

14. Lejeune TM, Willems PA, Heglund NC. (1989) Mechanics and energetics of human locomotion on sand. J Exp Biol 201:2071-2080

15. Maladen, R. D., Ding, Y., Li, C., and Goldman, D. I. (2009) Undulatory swimming in sand: subsurface locomotion of the sandfish lizard. Science 325, 314-318. doi: $10.1126 /$ science. 1172490

16. Marvi H, Gong C, Gravish N, Astley H, Travers M, Hatton RL, Mendelson JR $3^{\text {rd }}$, Choset H, $\mathrm{Hu}$ DL, Goldman DI. (2014) Sidewinding with minimal slip: Snake and robot ascent of sandy slopes. Science 346: 224-229. doi: 10.1126/science.1255718

17. Korff WL, McHenry MJ. (2011) Environmental differences in substrate mechanics do not affect sprinting performance in sand lizards (Uma scoparia and Callisaurus draconoides). $\mathrm{J}$ 
536

537

538

539

540

541

542

543

544

545

546

547

548

549

550

551

552

553

554

555

556

557

558

559

560

561

562

563

564

Exp Biol 214: 122-130. doi: 10.1242/jeb.045682

18. Crofts SB, Summers AP. (2011) Biomechanics: swimming in the sahara. Nature 472: 177178. doi:10.1038/472177a

19. Irschick DJ, Jayne BC. (1999) Comparative three-dimensional kinematics of the hindlimb for high-speed bipedal and quadrupedal locomotion of lizards. J Exp Biol 202:1047-1065.

20. Li C, Umbanhowar PB, Komsuoglu H, Koditschek DE, Goldman DI. (2009) Sensitive dependence of the motion of a legged robot on granular media. Proc Natl Acad Sci USA106: 3029-3034 doi: 10.1073/pnas.0809095106

21. Li C, Umbanhowar PB, Komsuoglu H, Goldman DI. (2011) The effect of limb kinematics on the speed of a legged robot on granular media. EXP MECH50: 1383-1393. doi: 10.1007/s11340-010-9347-1

22. Mazouchova N, Gravish N, Savu A, Goldman DI. (2010) Utilization of granular solidification during terrestrial locomotion of hatchling sea turtles. Biol Lett 6: 398-401. doi: $10.1098 /$ rsbl.2009.1041

23. Mazouchova N, Umbanhowar PB. Goldman DI. (2013) Flipper-driven terrestrial locomotion of a sea turtle-inspired robot.Bioinspir Biomim 8: 1748-3182. doi: 10.1088/1748$3182 / 8 / 2 / 026007$

24. Alexander R, Maloiy GMO, Njau R, Jayes AS. (1979) Mechanics of running in the ostrich (Struthio camelus). J Zool (Lond) 187: 169-178. doi: 10.1111/j.1469-7998.1979.tb03941.x

25. Abourachid A, Renous S. (2000) Bipedal locomotion in ratites (Palaeognatiform): examples of cursorial birds. Ibis 142: 538-549. doi: 10.1111/j.1474-919X.2000.tb04455.x

26. Williams JB, Siegfried WR, Milton SJ, Adams NJ, Dean WRJ, Du Plessis MA, Jackson Sue. (1993) Field metabolism, water requirements, and foraging behaviour of wild ostriches in the namib. Ecology 74: 390-404. doi: 10.2307/1939301

27. Watson RR, Rubenson J, Coder L, Hoyt DF, Propert MWG, Marsh RL. (2010) Gait-specific energetics contributes to economical walking and running in emus and ostriches. Proc R Soc B278: 2040-2046. doi: 10.1098/rspb.2010.2022

28. Rubenson J, Lloyd DG, Heliams DB, Besier TF, Fournier PA. (2011) Adaptations for economical bipedal running: the effect of limb structure on three-dimensional joint 
565

566

567

568

569

570

571

572

573

574

575

576

577

578

579

580

581

582

583

584

585

586

587

588

589

590

591

592

593

mechanics. J R Soc Interface 8: 740-755. doi: 10.1098/rsif.2010.0466

29. Smith NC, Wilson A M, Jespers KJ, Payne RC. (2006) Muscle architecture and functional anatomy of the pelvic limb of the ostrich (Struthio camelus). J Anat209: 765-779. doi: 10.1111/j.1469-7580.2006.00658.x

30. Fowler ME. (1991) Comparative clinical anatomy of ratites. J Zoo Wildl Med 22: 204-227.

31. El-Gendy SAA, DerbalahA, El-Magd MERA. (2011) Histo-morphological study on the footpad of ostrich (Struthio camelus) in relation to locomotion. J Vet Anat 4: 77-97.

32. Schaller NU, D'Août K, Villa R, Herkner B, Aerts, P. (2011) Toe function and dynamic pressure distribution in ostrich locomotion. J Exp Biol214: 1123-1130. doi: $10.1242 /$ jeb. 043596

33. Nasuno S, Kudrolli A, Gollub JP. (1997) Friction in granular layers: hysteresis and precursors. PHYS REV LETT79: 949-952.

34. Whittle MW. (1999) Generation and attenuation of transient impulsive forces beneath the foot: a review. GAIT POSTURE.10: 264-275. doi:10.1016/S0966-6362(99)00041-70

35. Daoud AI, Geissler GJ, Wang F, Saretsky J, Daoud YA, Lieberman DE. (2012) Foot strike and injury rates in endurance runners: a retrospective study. Med Sci Sports Exerc. 44: 13251334. doi:10.1249/MSS.0b013e3182465115

36. Lieberman DE, Venkadesan M, Werbel WA, Daoud AI, D'Andrea S, Davis IS, Mang'eni RO, Pitsiladis Y.. (2010) Foot strike patterns and collision forces in habitually barefoot versus shod runners. Nature 463: 531-535. doi: 10.1038/nature08723

37. Bramble DM., Lieberman DE. (2004) Endurance running and the evolution of Homo. Nature 432: 345-352. doi:10.1038/nature03052

38. Chia K, Schmitt D. (2005) Mechanical energy and effective foot mass during impact loading of walking and running. J Biomech 38: 1387-1395. doi: 10.1016/j.jbiomech.2004.06.020

39. Weissengruber GE, Egger GF, Hutchinson JR, Groenewald HB,Elsäser L, Famini D, Forstenpointner G. (2006) The structure of the cushions in the feet of african elephants ( Loxodonta africana ). J Anat 209: 781-792. doi: 10.1111/j.1469-7580.2006.00648.x

40. Gefena A, Megido-Ravid M, Itzchak, Y. (2001) In vivo biomechanical behavior of the human heel pad during the stance phase of gait. J BIOMECH 34: 1661-1665. doi: 
594

595

596

597

598

599

600

601

602

603

604

605

41. Geyer H, Seyfarth A, Blickhan R. (2006) Compliant Leg Behaviour Explains Basic Dynamics of Walking and Running [J]. Proceedings of the Royal Society B Biological Sciences, 273(1603):2861-2867.

42. O'Connor S M. (2009). The Relative Roles of Dynamics and Control in Bipedal Locomotion [D]. University of Michigan.

43. Hsieh S T, Lauder G V, Wake D B. (2004) Running on Water: Three-Dimensional Force Generation by Basilisk Lizards [J]. Proceedings of the National Academy of Sciences of the United States of America, 101(48):16784.

44. Falkingham P L, Gatesy S M. The birth of a dinosaur footprint: subsurface 3D motion reconstruction and discrete element simulation reveal track ontogeny.[J]. Proceedings of the National Academy of Sciences of the United States of America, 2014, 111(51):18279-84. 